\section{Is it necessary to repeat cervical cytology at the tie of a colposcopy?}

\section{É necessário repetir a citologia cervical no momento da colposcopia?}

Leticia Maria Correia Katz 1

Alex Sandro Rolland Souza 2

Juliana Melo de Moraes Guerra 3

Melania Maria Ramos Amorim 4

${ }^{1}$ Laboratório Central de Saúde Pública do Estado de Pernambuco (LACEN/PE). Recife, PE, Brasil.

2-4 Instituto de Medicina Integral Prof. Fernando Figueira (IMIP). Rua dos Coelhos, 300. Boa Vista. Recife, PE, Brasil. CEP: 50.070-550. E-mail: melamorim@uol.com.br

\section{Resumo}

Objetivos: avaliar se a repetição do Papanicolaou no momento da colposcopia melhora a concordância entre os métodos diagnósticos (citologia e histopatologia) do câncer do colo do útero.

Métodos: o estudo foi realizado no Laboratório Central de Saúde Pública do Estado de Pernambuco (LACEN/PE), de janeiro a julho de 2008, em 397 mulheres com exame citopatológico alterado encaminhadas para avaliação colposcópica. No momento da colposcopia, repetiu-se a citologia, em meio convencional. As duas citologias foram comparadas entre si e com o resultado do histopatológico obtido por biópsia dirigida pela colposcopia. A nomenclatura citológica utilizada foi Bethesda 2001 e a histopatológica a da Organização Mundial da Saúde (1994). A concordância entre os métodos foi avaliada pelo Kappa.

Resultados: comparando-se a citologia inicial com a citologia no momento da colposcopia, encontrou-se um Kappa de 0,297 (IC95\%: 0,235-0,359), considerado fraco. Com relação à concordância citológica-histopatológica observou-se, em relação à primeira citologia, um Kappa de 0,261 (IC95\%: 0,181-0,340) considerado fraco e em relação à segunda, um Kappa de 0,408 (IC95\%: 0,332-0,485) este último considerado moderado.

Conclusões: houve melhora da concordância citohistológica quando se repetiu a citologia no momento da colposcopia, depois de um primeiro exame alterado.

Palavras-chave Câncer do colo do útero, Esfregaço vaginal, Colposcopia 


\section{Introduction}

Cervical cancer represents a serious public health problem worldwide. ${ }^{1}$ Half a million new cases are estimated to have occurred in 2008 and 230,000 women are believed to have died of the disease. 1 More than half the new cases occur in developing countries and one-third of these are preventable. ${ }^{2}$

According to predictions of the incidence of cervical cancer in Brazil for the year 2008, 18,680 new cases were expected (19/100,000 women), making this neoplasia the third most common in the country. ${ }^{1}$ In the State of Pernambuco in the northeast of the country, the incidence of 22.73 cases $/ 100,000$ women is even higher than the figure for the country as a whole. ${ }^{1}$ The Papanicolaou test has been widely used around the world since 1943 as a cervical cancer screening method. ${ }^{3}$ Evidence shows that a well-organized program using the Papanicolaou (Pap) smear as a screening method is capable of reducing cervical cancer-related mortality by as much as $80 \% .4-6$ This is the method recommended by the US Preventive Services Task Force (USPSTF). ${ }^{7}$

Among the strategies used in Brazil to screen for cervical cancer, which consist of conventional cytology, liquid-based cytology and HPV DNA testing (hybrid capture for HPV), conventional cytology using the Pap smear method has been found to offer the best cost-benefit ratio. 8

According to the 2006 consensus guidelines of the American Society for Colposcopy and Cervical Pathology, repetition of the Pap smear after six months, colposcopy and HPV-DNA testing for oncogenic viruses are all accepted procedures for the adequate follow-up of atypical squamous cells of undetermined significance and low-grade squamous intraepithelial lesions in women over 20 years of age. 9

According to the literature, the repetition of the Pap smear after six months is an appropriate strategy in women with abnormal cytology. ${ }^{9}$ However, in Pernambuco, Brazil, patients with an abnormal Pap smear result are referred for colposcopy. 10 This test allows the observer to locate epithelial abnormalities (atypia) and to guide the biopsy. ${ }^{11}$

The accuracy of the Pap smear, as evaluated in the best-designed studies following selection in a systematic review, was considered moderate, sensitivity ranging from 30 to $70 \% .12$ When conventional cytology was compared with liquid-based cytology, the sensitivity of conventional cytology found in a metaanalysis was $55.2 \%$ for low-grade lesions and $75.6 \%$ for high-grade lesions. 13
Therefore, the aim of the present study was to eva-luate whether repeating Pap smear testing at the time of colposcopy improves agreement between diagnostic methods (cytology and histopathology) in cases of cervical cancer.

\section{Methods}

This cross-sectional study was carried out between January and July 2008 at the Women's Laboratory of the Central Public Health Laboratory for the State of Pernambuco (LACEN/PE), which is the reference laboratory for cytopathology and histopathology in the State of Pernambuco and is situated in the city of Recife, Brazil.

The women included in the study had been referred for colposcopy at LACEN/PE following a previous abnormal cytology result (cytology in conventional medium), defined as atypical squamous or glandular epithelial cells including invasive carcinoma. None of the women included in this study had undergone any prior treatment.

The sample size was calculated using the generally available OpenEpi software program, version 2 , and was based on data obtained in a pilot study carried out with the first 100 participants. The parameter used for calculating sample size was the frequency of atypical squamous cells (ASC) found in this sample population. 14 Considering a frequency of ASC of $12 \%$ in the initial cytology and $1 \%$ in the second cytology, for a confidence level of $99 \%$ and power of $90 \%, 326$ women would be required to detect this difference. The number was increased by approximately $20 \%$ to reach the final sample size of 397 women.

The age of these women ranged between 15 and 80 years (mean of 33 years with $63.7 \%$ in the $20-39$ year age group). The majority of the women (78.8\%) came from other municipalities of the State of Pernambuco, only 84 participants $(21.2 \%)$ being from the capital city of Recife or its surrounding metropolitan area.

At the time patients were submitted to colposcopy, samples were obtained for a second cytology in a conventional medium. These tests were all performed by the same investigator. Samples were collected from the ectocervix using an Ayres spatula and from the endocervix using a cytobrush (double sampling). The material was fixed with polyethylene glycol and stained using the Papanicolaou technique. 15 The nomenclature used was that defined in the 2001 Bethesda system terminology. 16

The initial cytology, which was the reason for 
later performing colposcopy, was carried out either at LACEN/PE or at another laboratory accredited by the state healthcare system. In the case of cytology carried out at the time of colposcopy, all samples were collected at LACEN/PE. The results from the two cytology tests were compared with each other and with the results of the histopathology, which was carried out at LACEN/PE in all cases.

In the cases where atypia were found on performing the colposcopy, a colposcopy-guided biopsy of the cervix was performed except in those patients who were pregnant, in which case the biopsy would only have been performed if microinvasion was suspected, and in situations of intense inflammatory processes, in which case the biopsy was scheduled to be performed following appropriate treatment.

The biopsy samples were submitted to histopathological examination using hematoxylin and eosin staining. The nomenclature used to report findings was that defined by the World Health Organization (WHO) in 1994, which classifies the histopathological grading of abnormalities found in the spectrum known as cervical intraepithelial neoplasia (CIN) into mild (CIN I), moderate (CIN II), severe (CIN III) or invasive carcinoma.

The time lapse between the two cytology tests varied from 21 to 465 days, with a median time interval of 75 days (or 3 months, when calculated in months rather than days) between them. In $66.9 \%$ of cases, the second cytology test was performed within 2-3 months of initial testing.

Of the total number of 397 patients, samples for the initial cytology test were taken at LACEN/PE in 305 cases $(76.8 \%)$, while 92 patients $(23.2 \%)$ underwent the sampling procedure in another reference laboratory. With respect to the second cytology tests, performed at the time of colposcopy, abnormalities were found in 214 of the tests $(71.16 \%)$ that had originally been performed at LACEN/PE and in 63 $(68.48 \%)$ of the tests that had been performed elsewhere. There was no statistically significant difference in the rate of abnormal findings in terms of the location where the initial cytology had been performed ( $p=0.758)$.

The Epi Info software program, version 3.5.3 and the Graphpad program were used for the statistical analysis. The chi-square test of association and Fisher's exact test were used, where appropriate, to compare the frequencies of findings in the first and second cytology tests. Kappa values and their 95\% confidence intervals $(95 \% \mathrm{CI})$ were used to analyze agreement between the two cytology tests and between each cytology test and histopathological findings. For analysis of the agreement between cytology and histopathology, the variables were recoded and grouped into similar categories for each test. A significance level of 5\% was adopted for all steps in the analysis.

The kappa coefficient is an index of agreement that varies from 0 to 1 in which 1 represents maximum agreement and 0 complete lack of agreement. In accordance with the values obtained, agreement was classified as poor (values below 0), slight $(0-0.2)$, fair $(0.21-0.4)$, moderate $(0.41-0.6)$, substantial $(0.61-0.8)$ and almost perfect agreement $(0.81-1) .{ }^{17}$

This project was approved by the internal review board of the Instituto de Medicina Integral Prof. Fernando Figueira (IMIP). All patients involved were duly informed of the aims of the study and were only admitted after agreeing to participate and signing an informed consent form.

\section{Results}

A higher percentage (48.4\%) of low-grade squamous intraepithelial lesions (LSIL) was found in the initial cytology tests compared to the repeat tests. On the occasion of the second cytology performed at the time of colposcopy, a higher frequency $(31.7 \%)$ of high-grade squamous intraepithelial lesions (HSIL) was found (Table 1).

In terms of the lesions detected on performing cytology, there was no statistically significant difference between the initial and repeat cytology tests with respect to atypical glandular cells (AGC; AGC not otherwise specified and AGC favoring neoplastic), adenocarcinoma in situ (AIS) or invasive lesions (squamous and glandular) (Table 1). On the initial cytology, the frequency of atypia in squamous cells, either atypical squamous cells of undetermined significance (ASC-US) (initial cytology $13.3 \%$ versus repeat cytology $1.0 \%$ ) or atypical squamous cells, without excluding high-grade squamous intraepithelial lesions (ASC-H) (initial cytology $4.8 \%$ versus repeat cytology $0.5 \%$ ) was significantly higher compared to the repeat cytology $(p<0.001)$.

Cases of LSIL were less frequent (initial cytology $48.4 \%$ versus repeat cytology $25.5 \%$; $p<0.001$ ), whereas cases of HSIL were significantly more frequent in the repeat cytology compared to the initial test (initial cytology $25.4 \%$ versus repeat cytology $31.7 \% ; p=0.049)$. In the cytology performed at the time of colposcopy, $30.3 \%$ of cases were considered negative for intraepithelial lesions or malignancy (NILM) (Table 1). 
Results of initial cytology and cytology performed at the time of colposcopy carried out at LACEN/Women's Laboratory, Pernambuco between January and July 2008.

\begin{tabular}{lccccc}
\hline & \multicolumn{2}{c}{ Initial cytology } & \multicolumn{2}{c}{ Repeat cytology } & \multirow{2}{*}{$\boldsymbol{p}$} \\
\cline { 2 - 5 } Cytological findings & $\mathrm{n}$ & $\%$ & $\mathrm{n}$ & $\%$ & \\
\hline NILM & - & - & 120 & 30.3 & \\
Adenocarcinoma in situ & 2 & 0.5 & 6 & 1.5 & $<0.0001^{*}$ \\
AGC not otherwise specified (NOS) & 3 & 0.8 & - & - & $0.143 *$ \\
AGC favors neoplasia & 1 & 0.3 & 1 & 0.3 & $0.125 *$ \\
ASC-US & 53 & 13.3 & 4 & 1.0 & $0.750 *$ \\
ASC-H & 19 & 4.8 & 2 & 0.5 & $<0.0001 *$ \\
Endocervical adenocarcinoma & - & - & 2 & 0.5 & $<0.0001 * *$ \\
Squamous cell carcinoma & 18 & 4.5 & 22 & 5.5 & $0.250 *$ \\
HSIL & 101 & 25.4 & 126 & 31.7 & $0.516 * *$ \\
HSIL with features suggesting invasion & 8 & 2.0 & 12 & 3.0 & $0.049 * *$ \\
LSIL & 192 & 48.4 & 102 & 25.7 & $0.359 * *$ \\
Total & 397 & 100.0 & 397 & 100.0 & $<0.0001 * *$ \\
\hline
\end{tabular}

NILM= negative for intraepithelial lesion or malignancy; $A G C=$ atypical glandular cells; $A S C-U S=$ atypical squamous cells of undetermined significance; $\mathrm{ASC}-\mathrm{H}=$ atypical squamous cells, not excluding high-grade squamous intraepithelial lesion; HSIL= high-grade squamous intraepithelial lesions; LSIL= low-grade squamous intraepithelial lesions; * Fisher's exact test; ** Chi-square test.

When initial cytology was compared with cytology performed at the time of colposcopy in the 192 women diagnosed with LSIL on initial cytology, the repeat cytology resulted in a diagnosis of HSIL in 34 cases and invasive carcinoma in one case, signifying that lesions were found to be more severe than indicated on initial cytology in $18.2 \%$ of cases. Of the 109 cases of HSIL and HSIL with features suggesting invasion, 85 cases $(78 \%)$ were found to correspond exactly to the initial diagnosis, while 4 were diagnosed as invasive, 2 as AIS and only two as LSIL.

Of the 397 women, atypia was detected on colposcopy in $347(87.4 \%), 334$ of whom were submitted to a biopsy. A biopsy was not performed on 11 women who were pregnant or on another 2 women who had intense inflammatory processes at the time of colposcopy and who failed to return after treatment. Of the 334 women on whom a biopsy was performed, histopathology findings were abnormal in $259(77.5 \%)$ (Figure 1)

Of the 334 patients who underwent a colposcopy-directed biopsy, $22.5 \%$ of the biopsies were found to be normal, while HPV-related atypia were found in $13.8 \%$ and $60.6 \%$ were classified as having some degree of cervical intraepithelial neoplasia (CIN I: $21 \%$, CIN II: $21.3 \%$ and CIN III: $18.3 \%$ ). Invasive squamous cell carcinoma was the most frequent form of cancer diagnosed (1.5\%), followed by microinvasive squamous cell carcinoma $(0.9 \%)$ and invasive cervical adenocarcinoma $(0.6 \%)$ (Table 2).

Of the 72 women who were found to have atypical squamous cells according to the initial cytology, 21 were not submitted to biopsy because there was no clinical indication, while 18 were considered NILM and 14 LSIL, making a total of 53 cases (73.6\%). Nevertheless, in the remaining 19 cases $(26.4 \%)$, histopathology classified 18 as HSIL and one as having an invasive lesion. On cytology performed at the time of colposcopy, a diagnosis of ASC was found in six cases, two of whom were not submitted to biopsy, while two received a negative histopathological result and two were considered LSIL.

With respect to a diagnosis of LSIL on initial cytology, 33 patients $(17.2 \%)$ were not submitted to biopsy and of the 159 who underwent biopsy, 39 $(20.3 \%)$ were considered NILM and $80(41.7 \%)$ LSIL (complete agreement between cytology and histopathology), while 39 (20.3\%) were diagnosed as HSIL and $1(0.5 \%)$ as having a microinvasive lesion. In $20.8 \%$ of cases, histopathology revealed a more severe diagnosis than that indicated by cytology. When cytology was repeated at the time of colposcopy, of the 102 women with LSIL, 10 (9.8\%) failed to undergo biopsy, 15 (14.7\%) had histopathological findings compatible with NILM, and 55 


\section{Figure 1}

Flowchart describing the follow-up of patients.

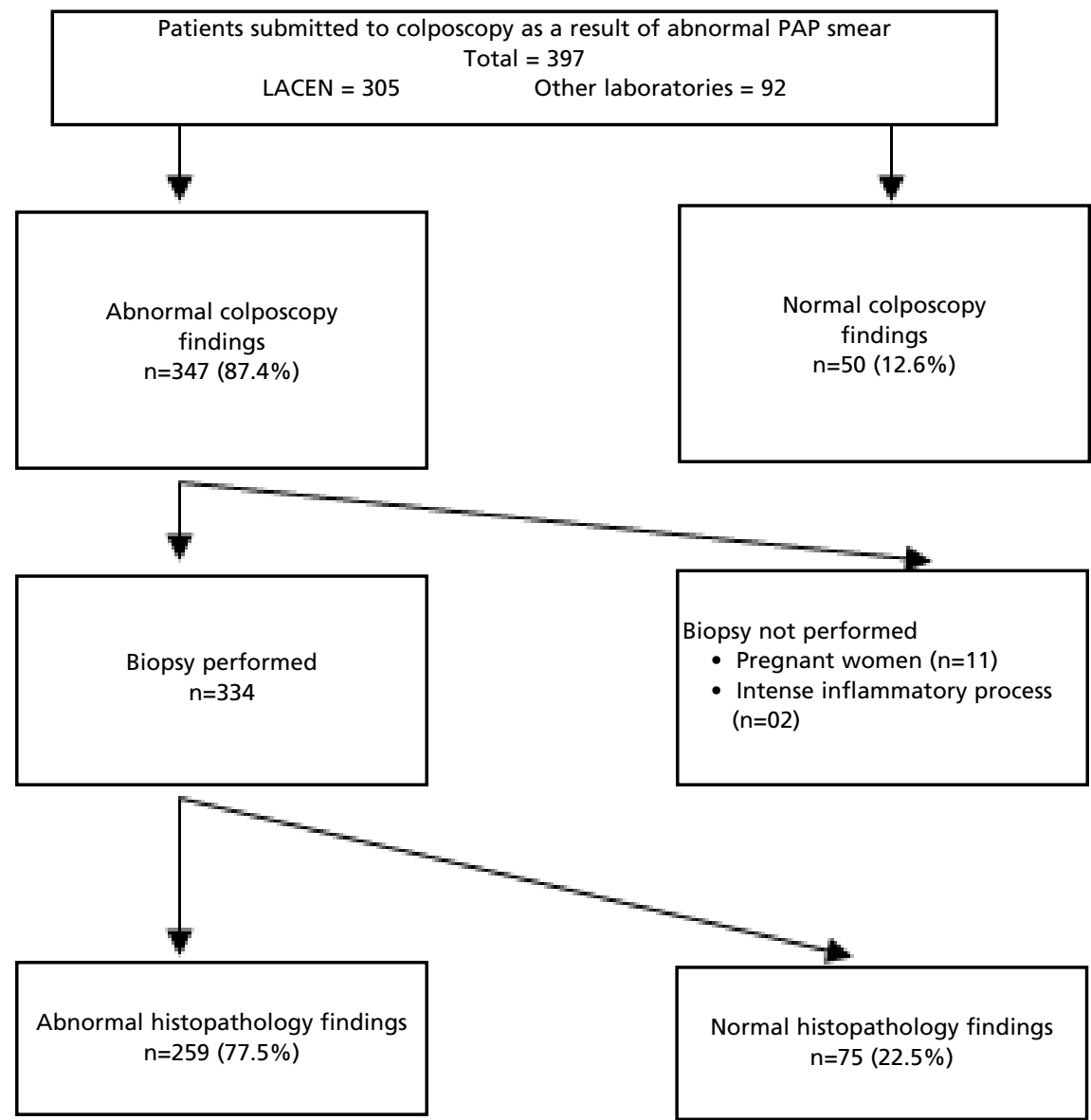

Table 2

Histopathology results of cervical biopsies carried out at LACEN/Women's Laboratory, Pernambuco between January and July 2008.

\begin{tabular}{lcc}
\hline Histopathology findings & N & $\%$ \\
\hline Adenocarcinoma in situ & 1 & 0.3 \\
Invasive cervical adenocarcinoma & 2 & 0.6 \\
Invasive squamous cell carcinoma & 5 & 1.5 \\
Microinvasive squamous cell carcinoma & 3 & 0.9 \\
HPV & 46 & 13.8 \\
CIN I & 70 & 21.0 \\
CIN II & 71 & 21.3 \\
CIN III & 61 & 18.3 \\
Normal & 75 & 22.5 \\
Total & 334 & 100.0 \\
\hline
\end{tabular}

$\mathrm{HPV}=$ human papiloma virus; $\mathrm{CIN} \mathrm{I}=$ cervical intraepithelial neoplasia mild; $\mathrm{CIN} \mathrm{II}=$ cervical intraepithelial neoplasia moderate; CIN III= cervical intraepithelial neoplasia severe. 
(53.9\%) had LSIL (complete agreement between cytology and histopathology); however, in $21.6 \%$ of cases, diagnosis was more severe than that indicated by cytology.

Of the cases of HSIL diagnosed by the second cytology, $97.8 \%(\mathrm{n}=135)$ were submitted to a biopsy, resulting in the following diagnoses: 15 cases of NILM (11.1\%), 27 of LSIL (20.0\%), 91 HSIL (67.4\%) (reflecting complete agreement between cytology and histopathology) and 2 cases (1.5\%) of microinvasive carcinomas.
Comparing the two cytology tests, a kappa coefficient of 0.297 was found (95\%CI: 0.235-0.359), which was considered fair. With respect to the agreement between cytology and histopathology, when the initial cytology results were compared with histopathology, the kappa coefficient was considered fair (0.261; 95\%CI: 0.181-0.340), while a kappa of 0.408 was found for the second cytology $(95 \% \mathrm{CI}$ : $0.332-0.485)$, which was considered moderate (Table 3).

Table 3

Analysis of overall agreement between the methods for the diagnosis of cervical cancer.

\begin{tabular}{lccc}
\hline Diagnostic method & Kappa & $\mathbf{9 5 \% \mathrm { Cl }}$ & Interpretation of agreement \\
\hline Initial cytology $x$ repeat cytology & 0.297 & $0.235-0.359$ & Fair \\
Initial cytology $x$ histopathology & 0.261 & $0.181-0.340$ & Fair \\
Repeat cytology $x$ histopathology & 0.408 & $0.332-0.485$ & Moderate \\
\hline
\end{tabular}

\section{Discussion}

The present study compared the results of cytology tests performed in women on two different occasions: an initial test that consisted of a routine screening test and a second at the time of colposcopy. When the results of the first and second cytology tests were compared, no statistically significant difference was found between the two in terms of the location where the initial cytology test was performed. This finding suggests that a similar level of diagnostic quality is maintained throughout the state healthcare network.

In view of the differences in the forms of management in cases of atypical squamous cells and LSIL, and the uniform manner in which cases of HSIL are dealt with, with treatment by conization being mandatory, this discussion will focus on the first two epithelial abnormalities since they represent situations in which differences in cytological and histopathological findings may lead to a change in conduct.

Data from the initial cytology tests showed a rate of ASC of $18.2 \%$, considerably higher than the $5 \%$ accepted in the literature as the maximum rate. ${ }^{18}$ In a Brazilian study carried out in cytopathology laboratories belonging to the Brazilian National Health Service (2007), this rate was $1.4 \% .{ }^{14}$ In the present study, when cytology was repeated at the time of colposcopy only in cases in which the results at initial cytology were abnormal, the rate of ASC fell to $2.2 \%$, a figure that is considered acceptable in the literature.14,18 The same occurred with LSIL, reported in $48.4 \%$ of initial tests and decreasing to $25.7 \%$ on the second analysis, which may suggest that repeating the test clarifies diagnosis in the case of squamous atypias and/or may indicate a change in cases of LSIL. The fact that, at the time of the colposcopy, the samples were collected by a trained physician, that this physician was aware of the previous abnormal diagnosis and that diagnosis was made by the same investigator in all cases, thereby permitting greater standardization of morphological criteria, should be taken into consideration since this may have favorably contributed towards clarifying diagnoses.

Repeating cytology at the time of colposcopy remains a controversial issue. Some studies show no advantages in this practice, which would result in a change of conduct in only $2 \%$ of lesions originally classified as LSIL and reclassified as HSIL on the second cytology. 19 Nevertheless, in the present study, $18.2 \%$ of cases diagnosed as LSIL at initial cytology were reclassified as HSIL or as an invasive lesion on the second cytology. The rates of LSIL diagnosed on cytology and later found to correspond to HSIL by histopathology were similar (around $21 \%$ ) for the two tests (initial cytology and cytology performed at the time of colposcopy). The literature reports rates of up to $20 \% .20$ 
Another study carried out a review of the medical charts of 2,830 women who were submitted to repeat cytology at the time of colposcopy to determine whether repeating the Pap smear would provide any clinical benefits that justified the clinical and financial costs. These investigators concluded that in 1,347 cases $(47.6 \%)$, diagnosis remained the same while clinical management changed in $2.7 \%$ of cases. Only $1.1 \%$ of patients were referred for conization, which raises questions regarding whether the cost-benefit ratio of repeating the test is advantageous. ${ }^{21}$ However, using the same comparisons, although the present findings show that diagnosis remained the same in 190 cases (47.86\%), changes in clinical management occurred in $21.27 \%$ of cases and in $19.03 \%$ of cases conization would be recommended. Therefore, even without taking into consideration the financial costs, a repeat cytology is beneficial in cases of ASC and LSIL.

According to conclusions reached by other authors, when initial cytology results in a low-grade lesion, it is clinically justifiable to repeat cytology at the time of colposcopy, since new cases of highgrade lesions were detected in that study when a repeat smear was performed. 22

Based on the assumption that a reduction in lowgrade lesions between an initial and repeat cytology smear may occur as a function of the time interval between the two tests, one study has shown that repeating the Pap smear resulted in no changes in cytological interpretation in cases of ASC and HSIL. On the other hand, in cases of LSIL, regression of the lesions was found, leading to an increase in the number of tests with results that were considered normal, from $28.3 \%$ on the initial cytology to $41.6 \%$ on the repeat test $(p<0.0001)$ when the interval between the first and second test was at least 184 days. ${ }^{23}$ With respect to the interval of time between the two cytology tests in the present study, in cases of LSIL $70.2 \%$ of repeat smear tests were performed within a maximum limit of 90 days, which favors the hypothesis that the better sampling conditions at the time of colposcopy rather than spontaneous regression are likely to be the reason for the more accurate diagnoses.

Better agreement would be expected for highgrade lesions; however, the fact that this was not found in the present study may be justified by the fact that an association should also be made between high-grade lesions and the results of conization, which was not performed in the present study.
Corroborating this theory, a study that compared the histopathological results of a colposcopy-directed biopsy with the results of excisional methods (conization or hysterectomy) concluded that in $26.2 \%$ of cases the lesion consisted of a grade II or higher intraepithelial neoplasia. ${ }^{24}$ Although data in the literature suggest that the collection of samples for cytology at the time of colposcopy may affect the quality of the colposcopic examination, it may indeed be beneficial to repeat cytology in women with a high-grade lesion (2005). ${ }^{25}$

In the present study, in which colposcopy was performed in all cases in which cytological abnormalities were found, followed by a biopsy whenever atypia were present o colposcopy, repeating cytology at the time of colposcopy would have been important in $10.6 \%$ of the cases. This percentage corresponds to those women who were found to have HSIL on the second cytology and in whom histopathology resulted in normal findings $(n=15)$ or LSIL $(n=27)$, reflecting disagreement between cytology and histology. In these cases of abnormal cytology on two different occasions and disagreement between cytology and histology, conization would be recommended for further clarification. In situations in which colposcopy cannot be performed immediately and standard management would consist of repeating cytology after six months, repeating cytology immediately when initial results were indicative of ASC or LSIL would probably be beneficial and would offer greater consistency in the referral of women for colposcopy.

There was an improvement in the agreement between cytology and histopathology when cytology was repeated at the time of colposcopy following an abnormal initial test. In the State of Pernambuco, morbidity and mortality rates for cervical cancer remain high and rates of ASC are above acceptable levels but return to acceptable levels when cytology is repeated at the time of colposcopy (initial cytology: $18.1 \%$; second cytology: $1.5 \%$ ).

Further studies are required to evaluate the benefits of repeating cytology immediately following a single abnormal finding or at the time of colposcopy, principally when bearing in mind that cytology diagnoses vary from place to place and from laboratory to laboratory. It would appear reasonable to repeat cytology immediately after an initial abnormal finding of ASC or LSIL in situations in which standard conduct consists of repeating cytology within a six month period. 


\section{References}

1. INCA (Instituto Nacional de Câncer). Ministério da Saúde. Estimativas 2008: incidência de câncer no Brasil. 2008. [Access on Sep 28 2008]. Available from: http://www.inca.gov.br/estimativa/2008/

2. INCA (Instituto Nacional de Câncer). Ministério da Saúde. Nomenclatura Brasileira para laudos citopatológicos cervicais e condutas clínicas preconizadas. Rio de Janeiro; 2003.

3. Anttila A, Ronco G, Clifford G, Bray F, Hakama M, Arbyn $\mathrm{M}$, Weiderpass E. Cervical cancer screening programmes and policies in 18 European countries. Br J Cancer. 2004; 91: 935-41.

4. Herrero R, Brinton LA, Reeves WC, Brenes MM, Britton RC, Gaitan E, Tenorio F. Screening for cervical cancer in Latin America: a case-control study. Int J Epidemiol. 1992; 21: 1050-6.

5. Van den Akker-van Marle ME, Van Ballegooijen M, Habbema JD. Low risk of cervical cancer during a long period after negative screening in the Netherlands. Br J Cancer. 2003; 88: 1054-7.

6. Gustafsson L, Pontén J, Zack M, Adami HO. International incidence rates of invasive cervical cancer after introduction of cytological screening. Cancer Causes Control. 1997; 8: 755-63.

7. The Guide to Clinical Preventive Services 2008. Recommendations of the U.S. Preventive Services Task Force. [Access on Oct 28 2008]. Available from: http://www.preventiveservices.ahrq.gov

8. Caetano R, Vianna CM, Thuler LC, Girianelli VR. Costeffectiveness of early screening of cervix neoplasms in Brazil. Physis: Rev Saúde Coletiva. 2006; 16: 99-118.

9. Wright TC Jr, Massad LS, Dunton CJ, Spitzer M, Wilkinson EJ, Solomon D. 2006 Consensus guidelines for the management of women with abnormal cervical cancer screening tests. J Low Genit Tract Dis. 2007; 11: 201-22.

10. Rocha S, Maia V. SOS Corpo Gênero e Cidadania. Atualização da Padronização de Normas e Procedimentos para a Prevenção do Câncer do Colo do Uterino no Estado de Pernambuco. Recife: Provisual divisão gráfica LTDA; 2000 .

11. Singer A, Monaghan JM. Exame para o pré-câncer cervical: colposcopia, patologia e tratamento do trato genital inferior. Porto Alegre: Artes Médicas; 1995.

12. Nanda K, McCrory DC, Myers ER, Bastian LA, Hasselblad V, Hickey JD, Matchar DB. Accuracy of the papanicolaou test in screening for and follow-up of cervical cytologic abnormalities: a systematic review. Ann Intern Med. 2000; 132: 810-9.

13. Arbyn M, Bergeron C, Klinkhamer P, Martin-Hirsch P, Siebers AG, Bulten J. Liquid compared with conventional cervical cytology: a systematic review and meta-analysis. Obstet Gynecol. 2008; 111: 167-77.

Recebido em 20 de julho de 2011

Versão final apresentada em 10 de maio de 2012

Aprovado em 12 de junho 2012
14. Thuler LC, Zardo LM, Zeferino LC. Perfil dos laboratórios de citopatologia do Sistema Único de Saúde. J Bras Patol Med Lab. 2007; 43: 103-14.

15. Liu W. A simplified cytologic staining technic. Am J Clin Pathol. 1970; 54: 767-8.

16. Solomon D, Davey D, Kurman R, Moriarty A, O'Connor D, Prey M, Raab S, Sherman M, Wilbur D, Wright T Jr, Young N. Forum Group Members. Bethesda 2001 Workshop. The 2001 Bethesda System: terminology for reporting results of cervical cytology. JAMA. 2002; 287: 2114-9.

17. Landis JR, Koch GG. The measurement of observer agreement for categorical data. Biometrics. 1977; 33: 159-74.

18. Solomon D, Frable WJ, Vooijs GP, Wilbur DC, Amma NS, Collins RJ, Davey DD, Knight BK, Luff RD, Meisels A, Navin J, Rosenthal DL, Sauer T, Stoler M, Suprun HZ, Yamauchi K. ASCUS and AGUS criteria. International Academy of Cytology Task Force summary. Diagnostic Cytology Towards the 21st Century. An International Expert Conference and Tutorial. Acta Cytol. 1998; 42: 1624.

19. Kourounis GS, Michail GD, Ravazoula P. A second Pap smear during colposcopy: is it really worth it? Eur J Gynaecol Oncol. 2004; 25: 475-7.

20. Frable WJ, Austin RM, Greening SE, Collins RJ, Hillman RL, Kobler TP, Koss LG, Mitchell H, Perey R, Rosenthal DL, Sidoti MS, Somrak TM. Medicolegal affairs. International Academy of Cytology Task Force summary. Diagnostic cytology towards the 21 st century: an International Expert Conference and Tutorial. Acta Cytol. 1998; 82: 76-119.

21. Spitzer M, Ryskin M, Chernys AE, Shifrin A. The value of repeat Pap smear at the time of initial colposcopy. Gynecol Oncol. 1997; 67: 3-7.

22. Zardawi IM, Rode JW. Clinical value of repeat Pap smear at the time of colposcopy. Acta Cytol. 2002; 46: 495-8.

23. Jeronimo J, Khan MJ, Schiffman M, Solomon D. ALTS Group. Does the interval between papanicolaou tests influence the quality of cytology? Cancer. 2005; 105: 133-8.

24. Molloy C, Dunton C, Edmonds P, Cunnane MF, Jenkins T. Evaluation of colposcopically directed cervical biopsies yielding a histologic diagnosis of CIN 1, 2. J Low Genit Tract Dis. 2002; 6: 80-3.

25. Dolman G, Tan J, Quinn M. Should the Pap smear be repeated at the first colposcopy visit? Aust N Z J Obstet Gynaecol. 2005; 45: 514-7. 